\title{
RELAÇÕES DE INTERDEPENDÊNCIA ENTRE CONFIANÇA, COMPROMETIMENTO, QUALIDADE PERCEBIDA E LEALDADE EM ESTUDANTES DO ENSINO SUPERIOR
}

\section{RELATIONS OF INTERDEPENDENCE BETWEEN TRUST, COMMITMENT, PERCEIVED QUALITY AND LOYALTY IN STUDENTS OF HIGHER EDUCATION}

\author{
Kenny Basso \\ Faculdade Meridional - IMED - Passo Fundo/RS \\ bassokenny@gmail.com
}

Elaine Aparecida Schwab Faculdade Pe. João Bagozzi, Curitiba/PR elaine_schwab@hotmail.com

Licione Torres Marques Isbert Faculdades Monteiro Lobato - Porto Alegre/RS licione@ hotmail.com

Luiz Antonio Slongo

Escola de Administração da Universidade Federal do Rio Grande do Sul - Porto Alegre/RS laslongo@ea.ufrgs.br

Submissão: $26 / 07 / 2013$

Aprovação: 02/09/2015 


\title{
RESUMO
}

A competitividade dos mercados, inclusive do mercado de ensino superior, tem forçado as organizações, neste caso as instituições de ensino superior, a melhorar a gestão da relação com seus clientes ou estudantes. Assim, o tema lealdade torna-se um estudo de extrema importância, inclusive no campo do ensino superior, o qual tem demonstrado um grande dinamismo, tanto pelo crescimento da demanda como pelo crescimento da oferta, aquecendo a competição principalmente junto às instituições privadas. Desta forma, o principal foco deste estudo é avaliar as relações de interdependência entre confiança, comprometimento, qualidade percebida e lealdade em estudantes de ensino superior. Os resultados mostraram que tanto a qualidade como o comprometimento têm uma forte participação na formação da lealdade, enquanto a confiança parece não relacionar-se diretamente com a lealdade, porém tendo uma participação forte na construção do relacionamento entre as partes, uma vez que relaciona-se significativamente com o comprometimento. Discussões e conclusões acerca dos resultados encontrados são apresentados ao final do artigo.

Palavras-Chave: Lealdade; Ensino Superior; Antecedentes da Lealdade.

\begin{abstract}
The competitiveness of markets, including the higher education market, has forced organizations, in this case the higher education institutions, to improve the relationship management with your customers or students. Thus, the loyalty issue is a study of extreme importance, including in the field of higher education, which has demonstrated great dynamism, both the growth of demand and the growth of supply, plus competition primarily with the private institutions. Thus, the main focus of this study is to assess the relationship of interdependence between trust, commitment, perceived quality and loyalty of students in higher education. The results showed that both the quality and commitment have a strong participation in the loyalty, while trust does not seem to relate directly with the loyalty, but taking a strong stake in building the relationship between the parties, since it significantly relates to the commitment. Discussions and conclusions about the results are presented in the end of the article.
\end{abstract}

Keywords: Loyalty; Higher Education; Antecedents of Loyalty. 


\section{INTRODUÇÃO}

A competitividade nos negócios provoca o desenvolvimento de ações no sentido de melhor entender os anseios do consumidor. Por esta razão, a compreensão das variáveis que conduzem à lealdade vem sendo estudada desde o início da década de 1970 (PRADO; SANTOS, 2003). A lealdade têm sido alvo de vários estudos acadêmicos e práticos, sendo por diversas vezes considerada como antecedente do desempenho organizacional (RUST et al., 2001; WOODRUFF, 1997). Este fenômeno pode ocorrer devido não só a um aumento do faturamento, mas também ocasionado pela redução dos custos de manutenção e captação de clientes, promovendo assim um acréscimo na lucratividade (REICHHELD; SASSER, 1990). As mudanças na lealdade e na retenção de clientes podem afetar de diferentes formas a lucratividade de uma empresa, e, portanto, devem ser consideradas.

Este impacto no desempenho pode ser notado em Instituições de Ensino Superior (IES), as quais vêm percebendo a necessidade de direcionar as ações de forma mais orientada ao mercado, tendo em vista a competitividade existente. Competição esta que pode ser corroborada com dados do Instituto Nacional de Ensino e Pesquisa (INEP, 2012), segundo o qual existem atualmente 2.378 IES no Brasil, sendo 2.100 privadas e 278 públicas. No estado do Rio Grande do Sul estão localizadas 115, sendo 105 privadas e 10 públicas.

$\mathrm{Na}$ área de administração, segundo o INEP (2012), são ofertados 4.621 cursos e ou habilitações em nível de graduação no país e 328 só no estado do Rio Grande do Sul, contexto esse, que demonstra um ambiente com uma enorme oferta de instituições e cursos, o que conduz, inexoravelmente, a uma concorrência acirrada. Tal situação conduz à necessidade do uso de estratégias mercadológicas mais eficazes, buscando fazer com que suas marcas e produtos obtenham vantagens competitivas frente aos concorrentes.

Frente a esta competição, as IES devem promover mudanças em suas formas de gestão, ensino, pesquisa e extensão, buscando oportunidades para estabelecer vínculos e contatos mais próximos e duradouros com o mercado. Considerando, neste aspecto, a presença da lealdade e a sua importância para a performance da instituição (HENNIGTHURAU et al., 2001). Neste sentido e em função do ambiente competitivo, Venkatesh (2001) afirma que o marketing em IES começou a ser trabalhado como ferramenta gerencial, uma vez que passaram a ser encontradas missões e objetivos desconexos com a realidade mercadológica; necessidade de sustentação para determinadas ações e departamentos; nascimento de programas e cursos similares; falta de diferenciações entre instituições 
concorrentes; redução de tempo por parte dos estudantes; necessidade de otimização dos recursos monetários; e o aumento do custo da instrução.

Diante desse ambiente, é importante compreender quais aspectos interferem na lealdade dos estudantes de IES e consequentemente, no desempenho competitivo das IES. Perin et al. (2004) realizaram um estudo sobre os antecedentes da lealdade e constataram que, por muito tempo, a satisfação foi considerada o construto-chave. Mais recentemente, estudos sobre serviços incluíram a qualidade, e em seguida a confiança e o comprometimento foram incluídos como fatores-chave para a predição desses comportamentos nos estudos sobre os antecedentes da lealdade (PARASURAMAN; GREWAL, 2000; SIRDESHMUKH et al., 2002; EVANSCHITZKY et al., 2006), encontrando apenas efeito marginais para a satisfação. Neste sentido, considera-se que a relação entre estudante e instituição seja explicada pela presença de percepção de qualidade do estudante, de confiança que este possui na IES, e do comprometimento do estudante com a IES.

Baseado no exposto, para aprofundar tal compreensão, este artigo objetiva verificar quais os efeitos da confiança, comprometimento e qualidade percebida na formação da lealdade de estudantes de instituições de ensino superior. Para tanto, o modelo de mensuração a ser utilizado será o modelo desenvolvido por Hennig-Thurau et al. (2001), onde a lealdade do estudante é determinada por três construtos: (1) a percepção do aluno da qualidade do serviço; (2) a confiança na instituição; (3) e o comprometimento à esta instituição. Especificamente, a aplicação deste modelo possibilita um aprofundamento no entendimento das relações entre os construtos e, ainda, é justificada pela preocupação com a lealdade do consumidor inclusive pelas instituições de ensino, em especial, as particulares.

\section{REFERENCIAL TEÓRICO}

Neste item serão discutidos os preceitos teóricos que embasam e norteiam os estudos empíricos desenvolvidos por esta pesquisa.

\subsection{Lealdade}

Inicialmente, a lealdade foi vista simplesmente como uma repetição de compra (OLIVER, 1999). Entretanto, como o campo do comportamento do consumidor maturou, pesquisadores perceberam que "a recompra não é uma evidência suficiente de lealdade à marca" e que as medidas padrões de compra incluem muitos incentivos à lealdade 
(NEWMAN; WERBEL, 1973, p. 404). Laran e Espinoza (2004) confirmam empiricamente que o índice de recompra nem sempre indica lealdade à empresa. Segundo eles, a compra pode ter sido em função de outros fatores, como preço, conveniência ou até mesmo lealdade a mais de uma marca. Dick e Basu (1994) ampliaram essa discussão e passaram a "representar" a lealdade por meio de uma combinação entre a atitude relativa à marca e a repetição de compra, gerando os conceitos de lealdade espúria e latente, analisando a lealdade pelas dimensões atitudinal e comportamental. Os autores afirmam que os clientes são leais a uma empresa desde que ambas as dimensões sejam positivas, isto é, elevada atitude aliada a uma elevada situação de recompra. Com este estudo, é possível afirmar que nem sempre que um consumidor compra repetidamente um produto ele está sendo leal, pois a compra pode estar sendo motivada exclusivamente por uma conveniência, ou seja, há situações de lealdade e de ausência de lealdade.

Desta forma, Oliver (1999, p. 34) vincula o construto da lealdade diretamente com o construto comprometimento, ao defini-la como "um profundo comprometimento do consumidor em continuar comprando um produto ou serviço, de determinado fornecedor, causando recompras da mesma marca ou empresa, independente de influências situacionais e esforços de marketing que poderiam causar um comportamento de troca”. Neste estágio, portanto, de lealdade última do consumidor, a que Oliver (1999) denominou ultimate loyalty - com profundo comprometimento de recompra -, os esforços de marketing da concorrência mostram-se incapazes de provocar a troca de marca ou empresa, bem como romper o relacionamento estável e duradouro existente. Para que este estágio de lealdade última seja atingido e, então, solidificada a relação entre cliente e empresa, o autor ressalta que deve haver a presença de determinismo pessoal e suporte social.

Sirdeshmukh et al. (2002, p. 20) definem a lealdade como "uma intenção em realizar um conjunto de comportamentos que sinalizam uma motivação de manter um relacionamento com uma empresa, incluindo um maior volume de negócios com a mesma, propaganda positiva, boca-a-boca e recompra”. E, neste cenário, construtos como confiança, percepção de valor e satisfação são considerados antecedentes da lealdade. No que se refere à razão das organizações pela busca da lealdade, Hennig-Thurau et al. (2001) afirmam que o entendimento de como as características do produto ou serviço contribuem para a mesma é necessário para compreender o que cria e determina o valor individual que deriva da marca. A finalidade é o alcance da lealdade, ou seja, ter os consumidores como defensores da marca. Neste mesmo ímpeto, Gounaris e Stathakopoulos (2004) classificam quatro tipos de lealdade: a não lealdade, que corresponde a nenhuma compra, uma falta de adesão à marca e, além 
disso, nenhuma influência social para haver lealdade à marca; a cobiça à lealdade, que se refere a nenhuma compra, mas uma forte e positiva predisposição para a marca, a qual é desenvolvida pelo envolvimento social e há disposição à recomendação, no entanto, por razões que o consumidor não pode controlar, a compra não acontece; a lealdade inercial, o consumidor escolhe a marca no lugar de outra, mas a escolha envolve pouco envolvimento emocional, pouco investimento pessoal e nenhum comprometimento; e a lealdade premium, na qual os autores defendem o alto nível de adesão à marca, alta incidência de recompra, e alta influência social, neste tipo de lealdade, o consumidor é impulsionado a realizar sacrifícios para viabilizar a aquisição da marca favorita. Nota-se que são estes últimos consumidores que mais contribuem para a comunicação boca-a-boca, conforme os autores dos tipos de lealdade apresentados.

No que tange a definição do estudo da lealdade, propriamente, é possível anotar que não existe unanimidade a respeito de sua definição, bem como dos seus antecedentes. HennigThurau e Klee (1997) sugerem que a qualidade, a confiança e o comprometimento relacionam-se entre si e são capazes de, direta ou indiretamente, influenciar a lealdade do consumidor. A proposta dos autores é que a lealdade é precedida pela qualidade percebida no relacionamento, que, por sua vez, é composta por três construtos: qualidade global de um serviço; confiança; e comprometimento de ambas as partes. Ademais, sob o ponto de vista destes autores, a qualidade percebida pode ser considerada como a satisfação do indivíduo com o serviço contratado.

Muito embora a evolução do tema, Hennig-Thurau et al. (2001) defendem que ainda cabe o aprofundamento da literatura sobre quais construtos - confiança, percepção de qualidade e comprometimento - seriam os principais responsáveis pela formação da lealdade e quais seriam menos significativos à sua formação, bem como quais os construtos precederiam uns aos outros.

\subsection{Confiança}

A confiança é tratada como um antecedente dos relacionamentos por representar a integridade e dignidade percebida por um parceiro no outro (MOORMAN et al., 1992; MORGAN; HUNT, 1994; GABARINO; JOHNSON, 1999; SIRDESHMUKH et al., 2002). Os julgamentos imparciais baseados na qualidade do tratamento interpessoal que o cliente recebe durante o encontro de serviço também desempenham seu papel na co-produção para 
geração de lealdade, através de influências nas atitudes e comportamentos do cliente (MASTERSON et al., 2000).

O construto confiança, de acordo com Perin et al. (2004), passou a desempenhar fundamental importância para as organizações devido à maior percepção de risco e incerteza para os clientes, principalmente sob a ótica dos serviços. Talvez seja por esta razão, que a confiança é vista como um ingrediente essencial para o sucesso dos relacionamentos (BERRY, 1995; DWYER et al., 1987; MOORMAN et al., 1993; MORGAN; HUNT, 1994). O conceito de confiança geralmente é apresentado sob dois aspectos: o primeiro é visto como crença, sentimento ou expectativa; e o outro é representado pelo comportamento (MOORMAN et al., 1992, 1993; SINGH; SIRDESHMUKH, 2000). Assim, Moorman et al. (1992) definem que a confiança pode ser vista como uma crença, sentimento ou expectativa sobre a lealdade do parceiro de troca, resultante de sua intenção, integridade ou competência. Este construto pode também representar um comportamento ou intenção de comportamento onde se coloca uma 'fé' no parceiro, podendo contar com ele, sempre que houver alguma possibilidade de vulnerabilidade ou incerteza por parte de quem confia, ou seja, a confiança seria preditora do conflito funcional, uma disposição a acreditar em um parceiro de trocas. Quanto menos conhecimento o consumidor possuir em relação a um produto ou serviço, dificultando o processo de avaliação, maior terá que ser seu nível de confiança em relação à empresa. Seguindo a mesma linha de raciocínio, Kramer (2000), propõe a segmentação do construto confiança como um estado psicológico e como uma escolha de comportamento. Por isto, Bitner (1995), propõe que cada encontro de serviço seja encarado como uma valiosa oportunidade para construir confiança, aumentando assim, a lealdade.

Os benefícios para os consumidores são importantes, principalmente nos casos de serviços onde, de acordo com Bejou et al. (1998), as informações assimétricas são significativas e o risco percebido associado à compra é alto. Considerando o risco associado aos serviços e a relação da experiência, o desenvolvimento da confiança está intimamente relacionado à duração do tempo do relacionamento (SWAN; NOLAN, 1985).

Os construtos confiança e comprometimento estão intimamente relacionados, como pode ser percebido nas definições apresentadas. Morgan e Hunt (1994) citam Acrol (1991) e concordam com o autor no que se refere à teoria da confiança e do comprometimento como mediadores, onde a confiança é considerada como um precursor do comprometimento. Paralelamente, Slongo e Müssnich (2005) concluem que a confiança é o principal determinante do comprometimento relacional, o que justifica sua importância como base nas relações. 
Empiricamente, analisando relacionamentos entre fornecedores e clientes, De Ruyter et al. (2001) encontraram que a confiança antecede a formação do comprometimento emocional. No mesmo sentido, ao investigar os antecedentes e consequências do comprometimento de consumidores (de casinos naquele estudo) Sui e Baloglu (2003) identificaram que o comprometimento emocional é positivamente antecedido pela confiança do consumidor. De um modo geral, a confiança já fora identificada como um construto importante nas relações entre os estudantes e IES por Neto e Moura (2004) que, no contexto nacional e quanto a uma instituição de ensino privada, encontraram uma relação positiva entre a confiança e o comprometimento. No entanto, no modelo proposto por Hennig-Thurau et al. (2001), a confiança apresentou uma relação significativa e positiva com o comprometimento emocional, o que leva a seguinte hipótese:

H1: A confiança dos estudantes na IES tem um impacto positivo no comprometimento emocional.

Berry (1993, p.1) afirma que "a confiança é a base para a lealdade". A constatação de que a confiança influencia positivamente a lealdade também é verificada no modelo desenvolvido por Brei e Rossi (2005), que investiga as consequências do construto confiança.

O modelo utilizado por Hennig-Thurau et al. (2001) analisa a relação direta da confiança na lealdade, a fim de obter uma melhor compreensão do construto quando é vislumbrado em instituições de ensino. Explorar o setor de serviços e verificar o impacto da confiança na lealdade torna-se crucial, uma vez verificado nos estudos de Sirdeshmukh et al. (2002) que confiar na empresa, em suas políticas e práticas gerenciais e ainda nos empregados a que se tem contato são fatores chaves para entender esta relação. De acordo com estes autores, os resultados mostraram que confiar nas práticas gerenciais da empresa conduz positivamente a lealdade, que pode ser explicada pela manutenção do relacionamento com essas organizações.

Neto e Moura (2004), não encontram uma relação significativa entre a confiança e a lealdade no contexto de IES, resultado este que vai ao encontro do exposto por HennigThurau et al. (2001) em seu estudo, pois estes encontraram resultados semelhantes. Todavia, diversos são os estudos que suportam esta ligação (CHAUDHURI; HOLBROOK, 2001; MACKINTOSH; LOCKSHIN, 1997). Chaudhuri e Holbrook (2001) encontraram que a confiança em uma determinada marca tem impacto em dimensões comportamentais e atitudinais da lealdade, pois a confiança é o ponto central dos relacionamentos de longa 
duração entre cliente e empresa. Já Mackintosh e Lockshin (1997) encontraram que confiança na marca foi um fator crítico para o surgimento da lealdade no contexto de varejo. No contexto de falhas em serviço Santos e Basso (2012) encontraram que a confiança na empresa possui uma ligação positiva com a intenção de recompra e a disposição a recomendar a empresa (enquanto facetas da lealdade).

Da mesma forma, quando Perin et al. (2004), analisaram o contexto de educação à distância e verificaram resultados semelhantes entre os clientes e a organização, no que tange a relação entre a confiança e a lealdade, mostrando que a característica do serviço analisado, ensino à distância, torna as percepções de confiança fundamentais na manutenção do relacionamento, evidenciando como a imagem da organização é importante no comportamento da lealdade.

Diante disso, como diversos estudos evidenciam uma ligação direta e positiva da confiança na lealdade, propõe-se a seguinte hipótese decorrente do construto confiança como variável chave para lealdade:

\section{H2: A confiança dos estudantes na IES tem um impacto positivo na lealdade.}

\subsection{Comprometimento}

O comprometimento é considerado um construto central do comportamento relacional com o consumidor (GARBARINO; JOHNSON, 1999), o que o faz ser considerado variável chave em modelos de relacionamento (MORGAN; HUNT, 1994).

No entanto, Prado e Santos (2003), constatam que a especificação da variável comprometimento ainda não está clara na literatura. A justificativa disso é a visão independente do construto, a exemplo de Morgan e Hunt (1994) e de Hennig-Thurau e Klee (1997), ou a vinculação entre os construtos comprometimento e lealdade, conforme descrevem Chaudhuri e Holbrook (2001). Por esta razão, Prado e Santos (2003) verificam e confirmam em seu estudo que os construtos de comprometimento e lealdade convergem fortemente para o mesmo conceito.

Ainda quanto à falta de clareza na definição de comprometimento, a teoria de Morgan e Hunt (1994) é questionada por Garbarino e Johnson (1999), pois os primeiros afirmam apenas que comprometimento e confiança são mediadores de relacionamentos eficazes. Garbarino e Johnson (1999) testaram hipóteses em que a confiança e o comprometimento são mediadores somente para relacionamentos considerados fortes com o consumidor, para 
relacionamentos fracos os construtos não são relevantes. As constatações dos autores indicam não somente a generalização da sua teoria para um contexto do consumidor, mas também identificam uma importante condição limitante.

Seguindo a linha da aproximação de conceitos, da mesma forma que foram tratadas no tópico anterior, as variáveis confiança e comprometimento apresentam uma forte ligação. Consumidores com forte relacionamento não somente possuem alto nível de confiança e comprometimento, mas também os tornam centrais em suas atitudes e estruturas de crenças (MORGAN; HUNT, 1994). Além disso, quando o comprometimento e a confiança - não apenas um ou outro - estão presentes, eles produzem resultados que promovem eficiência, produtividade e eficácia. A dependência e a alta influência da confiança no construto comprometimento são comprovadas no estudo de Slongo e Müssnich (2005), o que reforça os resultados obtidos por Garbarino e Johnson (1999) que também constatam que o comprometimento é considerado um antecedente das intenções futuras do cliente (intenções de revisitar, doar e afiliar-se a um teatro, conforme operacionalizado no estudo).

Para definir comprometimento, Morgan e Hunt (1994) o resumem como o desejo em manter uma relação válida, ou seja, quando um parceiro acredita que o relacionamento é tão importante que se justifica o máximo esforço em sua manutenção, nisto, a parte comprometida acredita que o relacionamento está 'funcionando' bem para garantir que ele perdure por tempo indefinido. Antes disso, Dwyer et al. (1987) já relacionavam o comprometimento a uma garantia implícita ou explícita na continuidade de um relacionamento entre os parceiros de troca. Mais adiante, a definição do construto para Hennig-Thurau e Klee (1997) considera aspectos afetivos e cognitivos, onde a orientação do consumidor voltada para o longo prazo em um relacionamento é baseada em aspectos emocionais e a convicção quanto à permanência no relacionamento traz mais benefícios que o término dele.

Outras consequências do comprometimento são apresentadas por Morgan e Hunt (1994), que citam o decréscimo de turnover, maior motivação, e aumento do comportamento organizacional de cooperação. Especialmente no caso de serviços, Berry e Parasuraman (1991) afirmam seguramente que o sucesso de um relacionamento depende do comprometimento mútuo.

O comprometimento entre um consumidor e uma organização pode afetar a lealdade, de modo que cria um sentimento de obrigação entre os atores (VIEIRA; DAMACENA, 2007). De um modo geral, diversos estudos têm encontrado relações entre o comprometimento e a lealdade (GRÖNROOS, 1994; PRITCHARD et al., 1999). 
Evanschitzky et al. (2006) encontram uma relação positiva entre o comprometimento (afetivo no estudo) e a lealdade tanto comportamental quanto atitudinal. No mesmo sentido, no contexto de serviços, Dean (2007) também evidenciou que o comprometimento, antecedido pela qualidade percebida, possui um efeito positivo na formação da lealdade.

Desta forma, também ocorre no contexto de ensino superior, onde os atores interagem na construção do serviço, tal como fora evidenciado por Neto e Moura (2004) quando da observância de uma relação positiva e significativa entre o comprometimento e a lealdade. Hennig-Thurau et al. (2001), analisaram o comprometimento sob diversos prismas: cognitivo, ou comprometimento calculado, definido como o sentimento de necessidade que o indivíduo tem em manter um relacionamento, baseando a relação em custos de trocas de modo frio e racional (VIEIRA; DAMACENA, 2007); emocional ou comprometimento afetivo que é definido como um interesse em continuar um relacionamento expressando sentimentos de lealdade baseados em estados emocionais e reciprocidades (VIEIRA; DAMACENA, 2007), e sob o comprometimento dos estudantes com o alcance de seus próprios objetivos. Ainda, Hennig-Thurau et al. (2001) também evidenciaram relações entre as facetas do comprometimento e a lealdade. Com base no exposto apresentam-se as seguintes hipóteses:

H3: O comprometimento emocional dos estudantes com a IES tem um impacto positivo na lealdade do estudante.

H4: O comprometimento cognitivo dos estudantes com a IES tem um impacto positivo na lealdade do estudante.

H5: O comprometimento com os objetivos dos estudantes tem um impacto positivo sobre a lealdade.

\subsection{Qualidade}

No sentido da manutenção do relacionamento, Zeithaml et al. (1996) acreditam que a qualidade é fator determinante na continuidade ou não com o serviço. $\mathrm{O}$ modelo de consequências comportamentais da qualidade do serviço tem início com a avaliação da qualidade pelo cliente (ZEITHAML et al., 1996). Quando as avaliações são boas, ou altas, as intenções comportamentais resultantes são favoráveis. Em contrapartida, quando as avaliações da qualidade do serviço são ruins, as intenções comportamentais são desfavoráveis e o relacionamento é mais propenso a ser enfraquecido. Essas intenções são indicadores de 
permanência ou não do indivíduo com a organização, isto é, indicam se o relacionamento entre as partes tende a durar ou não no tempo.

Espera-se que um serviço de qualidade superior tenha maior sucesso em gerar intenções comportamentais favoráveis e possa reduzir as ocorrências das intenções desfavoráveis (ZEITHAML et al., 1996), sugerindo que a propensão a compra repetida é mais suscetível quando o nível de qualidade é alto e as intenções favoráveis. Ao que Anderson e Sullivan (1993) encontram que uma melhora significativa na oferta do serviço concorrente pode fazer com que o consumidor troque de fornecedor.

Entretanto, uma IES que almeja desenvolver a estratégia baseada na qualidade para aumentar a taxa de lealdade dos seus estudantes, também precisa conhecer quais aspectos da qualidade dos serviços são mais importantes (HENNIG-THURAU et al., 2001). Por isto a importância do relacionamento com outros construtos como a confiança e o comprometimento, considerados tradicionais dimensões do relacionamento de qualidade, e que são pressupostos no modelo gerado por Hennig-Thurau et al. (2001).

Quanto a qualidade do serviço e as intenções comportamentais, Boulding et al. (1993) encontrou relações positivas ao analisar o contexto escolar, indicando que a qualidade faz com que as pessoas digam coisas positivas acerca da escola, planejem contribuir com dinheiro, e recomendem a escola para empregadores, como uma fonte de recursos valiosos.

A relação entre a qualidade e o comprometimento segundo Neto e Moura (2004) não é significativa, no entanto outros estudos comprovam que a relação no contexto de ensino superior existe, como exemplo tem-se o estudo de Hennig-Thurau et al. (2001), o qual identifica uma relação positiva e significativa entre a qualidade dos serviços e o comprometimento emocional. Fora do contexto educacional, mas no contexto de serviço, Dean (2007) comprova que a relação entre a qualidade percebida e comprometimento afetivo é positiva. O mesmo também é encontrado por Fullerton (2005) em dois diferentes contextos, loja de roupas masculinas e varejo de alimentos. A partir desta relação teórica, a qual mostra uma influência da qualidade sobre as respostas afetivas dos consumidores, propõe-se:

H6: A percepção dos estudantes quanto à qualidade do serviço tem um impacto positivo no comprometimento emocional.

O modelo conceitual de Hennig-Thurau et al. (2001) do construto de qualidade no relacionamento contêm três componentes: a qualidade percebida; a confiança do consumidor no relacionamento; e o comprometimento do consumidor. Neste modelo, o serviço de 
qualidade é visto como causador de um efeito positivo em ambos, confiança e comprometimento. Eles também propõem que a confiança, por si só, tem uma influência positiva no comprometimento. Para concluir, Hennig-Thurau e Klee (1997), afirmam que as três dimensões de qualidade no relacionamento mencionadas são consideradas antecedentes da lealdade do consumidor.

Em concomitante, a qualidade do serviço obteve uma correlação forte e significante com a confiança no estudo de Neto e Moura (2004). Ao dividir a qualidade em qualidade técnica e qualidade funcional, Eisingerich e Bell (2007) encontram que ambas as qualidades percebidas possuem um efeito sobre a confiança. Cho e Hu (2009) também encontraram efeito da qualidade percebida (analisada sob a perspectiva de cinco dimensões de qualidade) na confiança. Diante do exposto, acredita-se que a qualidade percebida pelo estudante possa ter uma relação positiva com a confiança que este desenvolve, ou seja, uma maior percepção de qualidade forma uma maior confiança.

No mesmo sentido da relação entre qualidade e confiança, Parasuraman et al. (1991) encontraram evidências de que a relação entre as percepções do consumidor quanto a qualidade do serviço e a propensão em recomendar a empresa é positiva e significativa. Boulding et al. (1993) encontraram relações positivas ao analisar o contexto escolar, indicando que a qualidade faz com que as pessoas digam coisas positivas acerca da escola, planejem contribuir com dinheiro e recomendem a escola para empregadores. Dean (2007) também evidencia que a qualidade percebida possui uma relação positiva com a lealdade. Assim, percebe-se que, tal como a confiança, a lealdade também pode ser antecedida positivamente pela qualidade que o sujeito percebe no serviço prestado.

No estudo de Hennig-Thurau et al. (2001) a qualidade do serviço é um dos principais antecedentes da lealdade no contexto de ensino superior, ao passo que a confiança também é precedida positivamente pela qualidade percebida pelo estudante. No caso deste trabalho e de acordo com a literatura apresentada, são propostas as próximas hipóteses de pesquisa onde se verifica a relação entre qualidade e confiança e o impacto direto da qualidade na lealdade do estudante.

H7: A percepção dos estudantes quanto à qualidade do serviço tem um impacto positivo na confiança.

H8: A percepção dos estudantes quanto à qualidade do serviço tem um impacto positivo na lealdade. 
A partir das relações acima discutidas e das hipóteses apresentadas de acordo com a revisão da literatura, a pesquisa utilizou-se da aplicação de um modelo teórico, adaptado de Hennig-Thurau et al. (2001), para analisar a lealdade e suas variáveis antecedentes em um contexto de IES

Figura 1 - Modelo Teórico Aplicado na Pesquisa

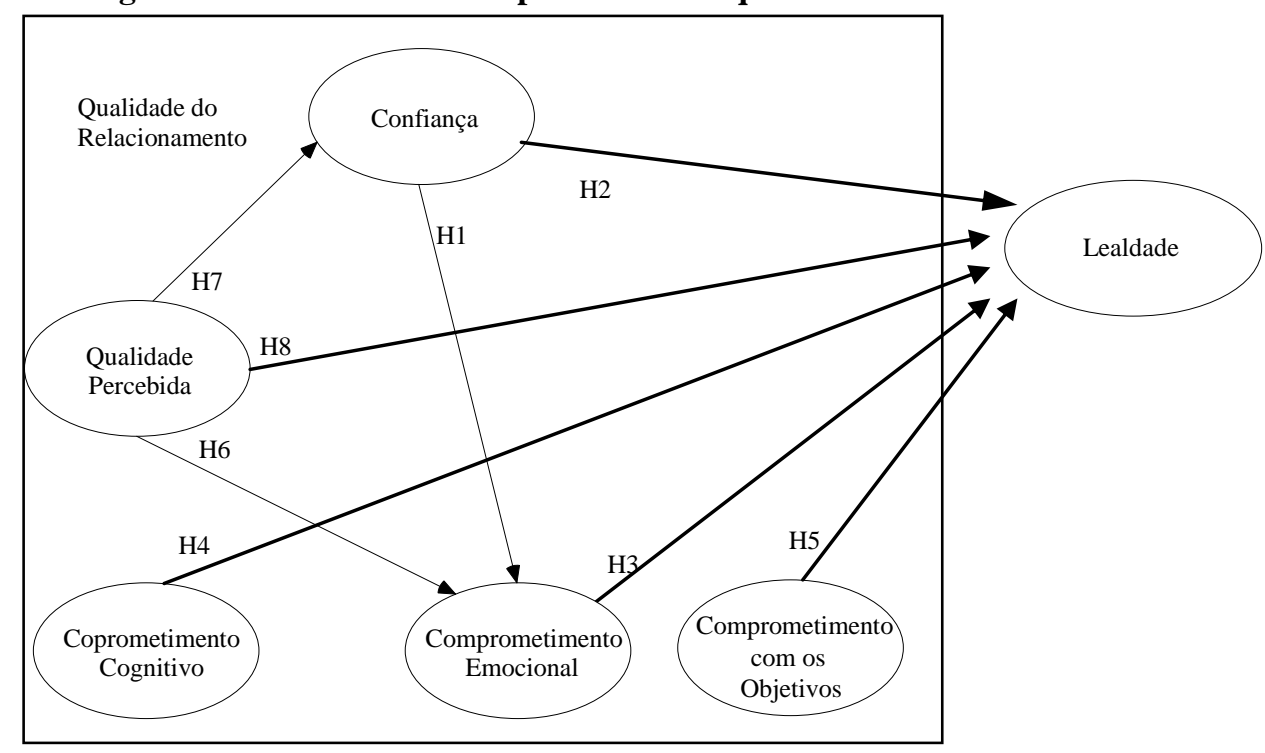

Fonte: Adaptado de Hennig-Thurau et al. (2001).

Os procedimentos metodológicos aplicados nesta pesquisa para avaliação do modelo proposto são descritos a seguir.

\section{MÉTODO}

Este estudo seguiu o método survey, em corte transversal de natureza descritivaquantitativa, seguindo os mesmos procedimentos que foram utilizados por Hennig-Thurau et al. (2001) para a utilização do modelo no contex to de ensino superior.

A população da pesquisa foi composta por estudantes de graduação em Administração de duas IES da região metropolitana de Porto Alegre - RS, ambas de cunho privado, uma considerada de grande porte (IESA), enquanto a outra, de médio-pequeno porte (IESB).

A amostragem do estudo caracterizou-se por ser não probabilística, enquadrada de acordo com Malhotra (2006) em uma amostragem por conveniência. O principal critério para dimensionar o tamanho da amostra requerida nesse estudo consistiu em verificar se o seu tamanho seria suficiente para permitir o uso das técnicas apropriadas de análise (HAIR et al., 1998). Para tanto, presume-se que, conforme utilizado por Hennig-Thurau et al. (2001), a 
modelagem de equações estruturais (MEE) seja a técnica mais adequada para testar e validar estruturas fundamentadas no modelo proposto. Assim, adotando-se a MEE, torna-se recomendável que o tamanho da amostra tenha, no mínimo, 5 respondentes por parâmetro estimado no modelo (HAIR et al., 1998). Nisto, o tamanho mínimo da amostra necessário para garantir a utilização da técnica de MEE é de 255 casos. No entanto, foram coletados 672 casos, que após o tratamento dos dados, foram reduzidos a 572 casos, sendo 280 casos da IESA e 292 casos da IESB.

$\mathrm{Na}$ amostra, 65,5 \% respondentes são homens (51,1\% na IESA; $71,6 \%$ na IESB); a média de idade foi de 25,2 anos (21,7 anos na IESA; 28,6 anos na IESB); e os mesmos ingressaram, em sua maioria, no ano de 2007, com previsão de formatura para 2011.

\subsection{Elaboração do Instrumento e Operacionalização dos Construtos}

As escalas utilizadas no estudo foram adaptadas do estudo feito por Hennig-Thurau et al. (2001), através de um processo de tradução reversa.

O conteúdo do questionário teve sua validade pelo método dos juízes e práticos. Foram utilizados como juízes dois pesquisadores de Marketing com pesquisas a respeito da temática; enquanto que como prático, foram entrevistados dois gestores de instituições de ensino. Posteriormente, foi realizado um pré-teste em cada IES, com a coleta de 30 casos em cada, através de entrevista pessoal executada pelos próprios pesquisadores.

Tal como apresentado no instrumento original (HENNIG-THURAU et al., 2001), os construtos foram mensurados por escala do tipo Likert de seis pontos, variando de "muito ruim" a "muito boa" e de "discordo totalmente" a "concordo totalmente", dependendo do enunciado da questão.

As escalas utilizadas no estudo foram adaptadas das utilizadas por Hennig-Thurau et al. (2001) e podem ser verificadas no quadro 1. Para verificar a unidimensionalidade dos construtos, foi feita uma análise fatorial exploratória, onde o resultado dos testes de esfericidade de Barlett e de adequação de amostra de Kaiser Meyer Olkin (KMO) recomendaram que os resultados fossem aceitos, comprovando a unidimensionalidade dos construtos utilizados.

Para atestar a confiabilidade de cada escala foi utilizada a medida alpha de Cronbach, para qual todos os construtos atingiram níveis maiores que os indicados como satisfatórios pela literatura (HAIR et al., 1998). Para atestar as validades convergente e discriminante utilizou-se a análise fatorial confirmatória (HAIR et al., 1998). O quadro 1 mostra os 
construtos, os indicadores correspondentes, seguidos pelo valor do alpha de Cronbach e pela variância extraída do construto, para cada amostra analisada.

Convém destacar também que as variâncias extraídas em cada construto encontram-se dentro das especificações mínimas contidas na literatura, que são de 60\% (HAIR et al., 1998), com a exceção da qualidade para a amostra da IESA que foi de 59\%, próximo ao nível desejável.

Quadro 1 - Construtos e Indicadores Utilizados

\begin{tabular}{|c|c|c|c|}
\hline Construto & Indicador & Alpha & $\begin{array}{l}\text { Variância } \\
\text { Extraída }\end{array}$ \\
\hline \multirow{5}{*}{ Qualidade } & como você avalia, em média, a competência dos professores; & \multirow{5}{*}{$\begin{array}{l}0,839^{1} \\
0,822^{2} \\
0,846^{3}\end{array}$} & \multirow{5}{*}{$\begin{array}{l}61,2 \%^{1} \\
59,0 \%^{2} \\
62,2 \%^{3}\end{array}$} \\
\hline & qual é a sua opinião sobre a orientação dada pelos professores; & & \\
\hline & avalie os critérios de avaliação utilizados; & & \\
\hline & avalie a oferta de serviços da universidade; & & \\
\hline & classifique os resultados que você está obtendo com seu curso. & & \\
\hline \multirow{3}{*}{ Lealdade } & eu recomendaria minha universidade para outra pessoa; & \multirow{3}{*}{$\begin{array}{l}0,801^{1} \\
0,720^{2} \\
0,873^{3}\end{array}$} & \multirow{3}{*}{$\begin{array}{l}73,0 \% 1 \\
64,1 \%{ }^{2} \\
80,5 \%^{3}\end{array}$} \\
\hline & $\begin{array}{l}\text { eu tenho muito interesse em manter-me em contato com minha } \\
\text { faculdade; }\end{array}$ & & \\
\hline & $\begin{array}{l}\text { se eu tivesse que tomar a decisão novamente, eu escolheria o } \\
\text { mesmo curso. }\end{array}$ & & \\
\hline \multirow{4}{*}{ Confiança } & $\begin{array}{l}\text { integridade é uma palavra adequada para descrever os } \\
\text { funcionários da universidade; }\end{array}$ & \multirow{4}{*}{$\begin{array}{l}0,889^{1} \\
0,868^{2} \\
0,903^{3}\end{array}$} & \multirow{4}{*}{$\begin{array}{l}75,1 \% 1 \\
71,8 \%^{2} \\
77,7 \%^{3}\end{array}$} \\
\hline & $\begin{array}{l}\text { eu estou certo de que os funcionários (técnicos-administrativos) } \\
\text { da universidade sempre agem com base no meu interesse; }\end{array}$ & & \\
\hline & $\begin{array}{l}\text { eu confio plenamente nos funcionários (técnicos-administrativos) } \\
\text { da universidade; }\end{array}$ & & \\
\hline & $\begin{array}{l}\text { os funcionários (técnicos-administrativos) da universidade } \\
\text { sempre cumpriram as promessas que fizeram para mim. }\end{array}$ & & \\
\hline $\begin{array}{l}\text { Comprometimento } \\
\text { cognitivo }\end{array}$ & eu escolhi esta universidade por razões práticas. & N.A. & N.A. \\
\hline $\begin{array}{l}\text { Comprometimento } \\
\text { com os objetivos }\end{array}$ & quando estabeleço metas para mim eu sempre as alcanço. & N.A. & N.A. \\
\hline \multirow{2}{*}{$\begin{array}{l}\text { Comprometimento } \\
\text { emocional }\end{array}$} & eu me sinto muito ligado a minha faculdade; & \multirow{2}{*}{$\begin{array}{l}0,848^{1} \\
0,784^{2} \\
0,892^{3}\end{array}$} & \multirow{2}{*}{$\begin{array}{l}86,8 \%^{1} \\
82,3 \%^{2} \\
90,3 \%^{3}\end{array}$} \\
\hline & eu sinto orgulho por poder estudar em minha universidade. & & \\
\hline
\end{tabular}

Fonte: Dados da Pesquisa.

1 Amostra total.

2 Amostra da IESA.

3 Amostra da IESB.

N.A. - Não Aplicável

Ainda referente a análise dos construtos, este estudo, seguindo as orientações de Anderson e Gerbing (1988), verificou as validades convergente e discriminante através de uma análise fatorial confirmatória. Ressalta-se que esta análise foi feita para a amostra geral, uma vez que os valores são semelhantes para as amostras das instituições. Os índices de ajuste encontrados para o modelo de mensuração $\left(\chi^{2}=181,064, g l=84, p=0,000 ;\right.$ GFI=0,96; RMSEA=0,045; AGFI=0,939; TLI=0,974; $\mathrm{CFI}=0,982 ; \mathrm{NFI}=0,966)$ indicaram um ajuste 
adequado, com exceção da significância do qui-quadrado, que pode ter influência do tamanho amostral e da quantidade de parâmetros estimados no modelo, e também do valor encontrado para o índice GFI, que evidencia um possível ajuste marginal do modelo, ao passo que essa última medida compara o modelo com um modelo nulo (HAIR et al., 1998).

A validade convergente dos construtos foi verificada através dos valores de $t$ dos indicadores, onde valores superiores a 1,96 (em valor absoluto) referem-se a convergência do indicador para o construto e denotam a existência desta validade (BAGOZZI et al., 1991). Neste aspecto, todos os indicadores apresentaram valores absolutos de $\mathrm{t}$ superiores a 1,96 quando relacionados a seus respectivos construtos, sendo que o menor valor de $\mathrm{t}$ encontrado foi da qualidade percebida $(11,95)$ e o maior da lealdade $(27,04)$. Já para verificar a validade discriminante, fez-se uso da técnica descrita por Fornell e Larcker (1981), que envolve a comparação entre a variância extraída e a compartilhada entre os construtos. Todos os construtos tiveram sua validade discriminante verificada, uma vez que a maior variância compartilhada encontrada foi de 0,56 , entre a lealdade e o comprometimento emocional, não superando, desta forma, as variâncias extraídas de ambos os construtos que foram, respectivamente, $73,0 \%$ e $86,8 \%$.

\subsection{Coleta e Tratamento dos Dados}

A pesquisa foi operacionalizada por um questionário entregue e recolhido em mãos, aplicado em sala de aula na IESA, e no ato da rematrícula na IESB. Para a coleta de dados em sala de aula, foi solicitado aos professores que cedessem um espaço da aula para que os alunos pudessem responder o instrumento de pesquisa. Já no ato da matrícula, foi entregue o instrumento aos alunos que estavam realizando a rematrícula, e portanto, aguardando para serem atendidos. Em ambos os casos, foi informado aos alunos que tratava-se de uma pesquisa acadêmica e que o objetivo era compreender as percepções dos alunos. Foi garantido aos alunos o anonimato bem como o direito de não participar da pesquisa.

A coleta dos dados foi realizada pelos próprios pesquisadores autores deste artigo. Ela aconteceu no período de 20/11 a 10/12 de 2007 e no ato da rematrícula na IESB, no período de 7 a 11/01 de 2008.

Após coletados, os dados foram tratados no Software SPSS®, a fim de preparar a matriz de entrada de dados. Para tanto, foi analisada a qualidade do banco de dados; os missing values, que foram substituídos pela média em cada variável, sendo que não foram encontrados valores maiores que 5\% em missing values para cada variável; os outliers, foram 
identificados por estatísticas uni (teste z) e multivariadas (distância D² de Mahalanobis), e após retirados da análise; a normalidade dos dados foi comprovada por meio de cálculos de assimetria e curtose; enquanto a multicolinearidade foi verificada por meio de cálculos de correlação bivariada e pelo cálculo de tolerância, não sendo encontrado nenhum caso; por fim, a homocedasticidade dos dados foi verificada por meio do teste de Levene (HAIR et al., 1998). Após os testes, a base de dados foi considerada adequada para os procedimentos de análise por meio da MEE.

\section{RESULTADOS}

A análise dos dados, que será apresentada na sequência, foi feita através de MEE, conforme anteriormente já mencionado. Os resultados são apresentados em três tabelas: a tabela 1 apresenta os resultados para a amostra total; a tabela 2 apresenta os resultados da IESA; enquanto a tabela 3 evidencia os resultados encontrados na amostra da IESB. Cada tabela mostra os caminhos estruturais preconizados pelo modelo, seus respectivos coeficientes de regressão $(\beta)$ e coeficientes de significância, bem como os coeficientes de explicação $\left(\mathrm{R}^{2}\right)$ para cada construto examinado. Ainda, nas tabelas que seguem, são apresentados os índices de ajuste para o modelo em cada situação.

Tabela 1 - Resultados para a Amostra Total.

\begin{tabular}{|c|c|c|c|c|}
\hline Caminhos estruturais & Coeficientes & Sig. & $\mathbf{R}^{2}$ & Índices de ajuste \\
\hline Comprometimento emocional $\leftarrow$ Confiança & 0,34 & 0,001 & \multirow{2}{*}{0,59} & \multirow{2}{*}{$\begin{array}{l}\chi^{2}: 370,366 \mathrm{p}<0,001 \\
\chi^{2} / \mathrm{GL}: 4,209\end{array}$} \\
\hline Comprometimento emocional $\leftarrow$ Qualidade & 0,48 & 0,001 & & \\
\hline Confiança $\leftarrow$ Qualidade & 0,74 & 0,001 & 0,55 & GFI: 0,932 \\
\hline Lealdade $\leftarrow$ Qualidade & 0,27 & 0,001 & \multirow{5}{*}{0,78} & RMSEA: 0,075 \\
\hline Lealdade $\leftarrow$ Confiança & 0,02 & $0,676^{*}$ & & AGFI: 0,895 \\
\hline Lealdade $\leftarrow$ Comprometimento emocional & 0,63 & 0,001 & & TLI: 0,927 \\
\hline Lealdade $\leftarrow$ Comprometimento cognitivo & 0,07 & 0,021 & & CFI: 0,946 \\
\hline Lealdade $\leftarrow$ Comprometimento com objetivos & 0,08 & 0,005 & & NFI: 0,931 \\
\hline
\end{tabular}

* Valores não significativos a $\mathrm{p}<0,05$.

Fonte: Dados da Pesquisa.

Tabela 2 - Resultados para a Amostra da IESA

\begin{tabular}{|c|c|c|c|c|}
\hline Caminhos estruturais & Coeficientes & Sig. & $\mathbf{R}^{2}$ & Índices de ajuste \\
\hline Comprometimento emocional $\leftarrow$ Confiança & 0,36 & 0,001 & \multirow{2}{*}{0,47} & \multirow{8}{*}{$\begin{array}{l}\chi^{2}: 233,248 \mathrm{p}<0,001 \\
\chi^{2} / \text { GL: } 2,651 \\
\text { GFI: } 0,915 \\
\text { RMSEA: } 0,077 \\
\text { AGFI: } 0,868 \\
\text { TLI: } 0,906 \\
\text { CFI: } 0,931 \\
\text { NFI: } 0,896\end{array}$} \\
\hline Comprometimento emocional $\leftarrow$ Qualidade & 0,38 & 0,001 & & \\
\hline Confiança $\leftarrow$ Qualidade & 0,74 & 0,001 & 0,54 & \\
\hline Lealdade $\leftarrow$ Qualidade & 0,23 & 0,020 & \multirow{5}{*}{0,83} & \\
\hline Lealdade $\leftarrow$ Confiança & $-0,05$ & $0,605^{*}$ & & \\
\hline Lealdade $\leftarrow$ Comprometimento emocional & 0,78 & 0,001 & & \\
\hline Lealdade $\leftarrow$ Comprometimento cognitivo & $-0,06$ & $0,312 *$ & & \\
\hline Lealdade $\leftarrow$ Comprometimento com objetivos & 0,06 & $0,207 *$ & & \\
\hline
\end{tabular}


Tabela 3 - Resultados para a Amostra da IESB

\begin{tabular}{|c|c|c|c|c|}
\hline Caminhos estruturais & Coeficientes & Sig. & $\mathbf{R}^{2}$ & Índices de ajuste \\
\hline Comprometimento emocional $\leftarrow$ Confiança & 0,39 & 0,001 & \multirow{2}{*}{0,61} & \multirow{2}{*}{$\begin{array}{l}\chi^{2}: 239,112 \mathrm{p}<0,001 \\
\chi^{2} / \mathrm{GL}: 2,717\end{array}$} \\
\hline Comprometimento emocional $\leftarrow$ Qualidade & 0,44 & 0,001 & & \\
\hline Confiança $\leftarrow$ Qualidade & 0,74 & 0,001 & 0,55 & GFI: 0,917 \\
\hline Lealdade $\leftarrow$ Qualidade & 0,30 & 0,001 & \multirow{5}{*}{0,74} & RMSEA: 0,077 \\
\hline Lealdade $\leftarrow$ Confiança & 0,05 & $0,469 *$ & & AGFI: 0,872 \\
\hline Lealdade $\leftarrow$ Comprometimento emocional & 0,50 & 0,001 & & TLI: 0,934 \\
\hline Lealdade $\leftarrow$ Comprometimento cognitivo & 0,19 & 0,001 & & CFI: 0,952 \\
\hline Lealdade $\leftarrow$ Comprometimento com objetivos & 0,12 & 0,002 & & NFI: 0,927 \\
\hline
\end{tabular}

* Valores não significativos a $\mathrm{p}<0,05$.

Fonte: Dados da Pesquisa.

De um modo geral, a tabela 1 apresenta os índices de ajuste do modelo, que foram satisfatórios, ressalva feita para o índice de qualidade de ajuste calibrado (AGFI) que ficou levemente abaixo no nível mínimo indicado pela literatura (HAIR et al., 1998). No entanto, Hair et al. (1998) consideram que o modelo possa ser aceito, visto que o índice - AGFI encontra-se próximo dos níveis desejáveis e que os outros índices estão de acordo com o recomendado.

Para verificar se os resultados encontrados são dependentes da amostra total analisada, optou-se por verificar o modelo, e também os caminhos estruturais nas amostras coletadas na IESA e IESB. Quando subdividas as amostras, em IESA (tabela 2) e IESB (tabela 3), os indicadores de ajuste foram menores que para a amostra total. $\mathrm{O}$ modelo apresentou um ajuste melhor quando aplicado a IESB em comparação com a IESA. Convém destacar que nos indicadores de ajuste apresentados para o modelo aplicado à IESA, além do AGFI, o índice de ajuste NFI apresentou valor um pouco abaixo do nível recomendado pela literatura, que é de 0,90 (HAIR et al. 1998). Utilizando-se o mesmo argumento para aceitação do AGFI, aceitouse também o NFI, embora levemente fora do padrão recomendado. O caminho estrutural, estabelecido pelo modelo, entre a confiança e o comprometimento emocional foi significativo e positivo em todas as amostras, provendo assim sustentação para Hipótese 1. Também condizente com o comprometimento emocional, foi verificado que a qualidade percebida é um importante antecedente deste construto, uma vez que todos os coeficientes de regressão foram significativamente positivos, garantindo suporte à Hipótese 6 do estudo. Tendo a confiança e a qualidade percebida como antecedentes, o comprometimento emocional tem um bom nível de variância explicada, que na amostra total foi de $59 \%$, já na comparação entre as duas IES, a IESB obteve um índice de explicação de variância maior (61\%) do que a IESA (47\%), no entanto, ambos os índices permitem verificar a capacidade preditiva dos antecedentes do comprometimento emocional. 
A confiança, por sua vez, como preconiza a Hipótese 7, devia ter como antecedente a qualidade, relacionamento este que foi comprovado pela aplicação do modelo, onde os coeficientes de regressão foram positivos e significativos, confirmando a hipótese. Em termos de explicação, o modelo geral evidencia que $55 \%$ das variações da confiança são explicadas pelos antecedentes.

Com o foco do estudo voltado para a verificação das relações entre qualidade, comprometimento e confiança com a lealdade em um contexto de ensino superior, foi encontrado que a lealdade possui boa variância explicada pelos seus antecedentes $(78 \%$ na amostra geral). Quanto aos antecedentes, o comprometimento emocional foi o mais significativo, uma vez que na IESA esta relação foi da ordem de $\beta=0,78$ e na IESB de $\beta=$ 0,50, ambos significativos e positivos, o que provê suporte à aceitação da Hipótese 3. A qualidade percebida também teve um impacto significativo na lealdade do estudante, uma vez que apresentou coeficientes significativos e positivos, suportando a Hipótese 8.

O comprometimento cognitivo e o comprometimento com os objetivos demonstraram relações frágeis para com a lealdade, pois na amostra geral tiveram, mesmo que com coeficientes baixos, relações significativas e positivas com a lealdade, no entanto, os resultados apresentados pela amostra da IESA mostram que estes construtos não têm uma relação significativa com a lealdade, fazendo com que a aceitação das Hipóteses 4 e 5 seja parcial. Isto devido a confirmação da relação na amostra da IESB, que por sua vez apresenta coeficientes relativamente maiores e mais significantes que na amostra da IESA.

Por fim, o caminho estrutural que preconizava uma ligação direta e positiva entre a confiança e a lealdade não teve sua significância comprovada em nenhuma das amostras, fazendo com que a Hipótese 2 do estudo fosse rejeitada.

De forma sintética, apenas uma hipótese, portanto, foi rejeitada $(\mathrm{H} 2)$ e outras duas $(\mathrm{H} 4$ e H5) foram aceitas parcialmente, sendo que o restante das hipóteses foram comprovadas pelos resultados encontrados.

\subsection{Discussão dos resultados}

A confiança, diferentemente do encontrado por Sirdeshmukh et al. (2002), não atua como um antecedente da lealdade no contexto de ensino superior, resultado este que também foi encontrado por Neto e Moura (2004) e Hennig-Thurau et al. (2001), quando este segmento foi estudado. No setor de ensino, este construto parece ter uma aplicabilidade maior quando analisado a educação à distância (PERIN et al., 2004), uma vez que a falta de contato pessoal 
pode fazer com que os níveis de confiança gerem a lealdade. Enquanto no modelo de ensino presencial - com contato físico - como mostram os resultados da pesquisa, a qualidade atuou, significativamente, como antecedente da lealdade. Para tanto, a confiança neste contexto ainda carece de estudos que possam verificar suas implicações na lealdade.

O que reforça ainda mais a necessidade de contato pessoal para gerar a lealdade é a relação encontrada entre o comprometimento emocional e a lealdade. $\mathrm{O}$ comprometimento, como tratam Vieira e Damacena (2007), cria uma relação de obrigação e dependência entre os participantes do relacionamento, fazendo com que a instituição, na qual o aluno estuda, seja alvo de indicações, recomendações e comentários positivos, indicadores da lealdade. O comprometimento emocional possui facetas que em muito se assemelham as apresentadas pelo construto da lealdade, quando tangenciam os sentimentos de afeto e apego a uma determinada marca (OLIVER, 1999; PRADO; SANTOS, 2003). Embora não tenha apresentado uma relação significativa com a lealdade, a confiança é importante para a geração de um comprometimento emocional. Com isso, maiores níveis de confiança que o estudante possui na IES traduzem-se em maiores níveis de comprometimento emocional, que por sua vez, incorre em maiores níveis de lealdade.

As relações pessoais, que possuem uma condição de objetividade, por sua vez, são expressas pelo construto da qualidade percebida, que tem um impacto significativo na lealdade do estudante. Tal como afirmam Zeithaml et al. (1996) quanto maior a percepção da qualidade do serviço prestado, maior tenderá a ser a lealdade do sujeito, que por sua vez também terá uma maior propensão a engajar-se mais com a instituição, como mostrado pela relação entre a qualidade e o comprometimento emocional. Boulding et al. (1993) também afirmam que, assim como o encontrado nesta pesquisa, a qualidade conduz a intenções mais favoráveis à instituição, bem como a um nível de apego sentimental maior quando a qualidade percebida encontra-se acima dos níveis desejáveis. A qualidade percebida também faz com que os estudantes tenham maiores níveis de confiança na instituição, evidenciando a importância da qualidade na construção de relacionamentos mais duradouros e mais parcimoniosos entre a instituição e o aluno, uma vez que a confiança retrata a capacidade de confiar e aceitar as proposições da instituição com a qual mantém-se a relação (MOORMAN et al., 1992).

Diante do exposto a qualidade percebida pelo estudante é um construto importante para a criação tanto de relacionamentos mais duradouros (comprometimento emocional e confiança) quanto para a manifestação de comportamento de indicação e recompra da instituição (lealdade). 
Contrário as relações mencionadas, tanto o comprometimento cognitivo quanto o comprometimento com os objetivos demonstraram relações diferentes com a lealdade entre as amostras utilizadas. Enquanto o comprometimento emocional envolve o sentimento de pertencimento e, no contexto estudado, pode refletir o carinho e o afeto pela instituição de formação, o comprometimento cognitivo e com os objetivos refletem uma ligação mais forte com a IES. Este comprometimento mais forte inclui não somente o aspecto emocional, mas também envolve uma identificação racional e com o que a IES se propõe, seus objetivos e suas crenças. Diante disso, acredita-se que o tamanho da IES possa influenciar no surgimento e manutenção destes tipos de comprometimento (cognitivo e com os objetivos), uma vez que em instituições menores, como a IESB, o contato e a participação dos alunos na IES se torna mais intensa e exige um maior nível de comprometimento. Embora o estudo não disponha de dados para sustentar tal suposição, sugere-se que estudos futuros possam averiguar tal diferença entre instituições e analisar como esta diferença interfere na relação entre os tipos de comprometimento e a lealdade.

\section{Conclusão}

O modelo estudado obteve adequação ao contexto de ensino superior, evidenciando que a lealdade é significativamente e diretamente predita pelo comprometimento emocional e pela qualidade percebida pelo estudante na instituição.

O estudo demonstra que, visto a competitividade do setor, o Marketing em IES deve atentar para questões ligadas não só a satisfação dos seus alunos, mas também à criação e manutenção de relacionamentos mais estáveis e duradouros, criando formas estratégicas de inferir no comportamento destes. A qualidade e o comprometimento emocional são as formas mais eficazes para a construção da lealdade no ambiente de ensino superior. Já a confiança ainda carece de estudos que comprovem a sua ligação direta com a lealdade, todavia, sua presença no modelo está relacionada com a construção do comprometimento emocional.

A interpretação do estudo deve destacar as limitações que concernem quanto a utilização de uma abordagem de corte transversal, que não abrange as modificações ao longo do tempo; e na participação de indivíduos, na amostra, com ingresso, em sua maioria, no ano de 2007, ou seja, com pouco tempo de interação com a instituição. Além disso, considera-se que o uso de uma amostragem por conveniência possa limitar o poder de generalização dos resultados. Embora a intenção do estudo esteja em testar as relações teóricas e a adequação do modelo, os resultados carecem de generalização devido ao procedimento amostral utilizado. 
Neste sentido, sugere-se que estudos futuros possam utilizar processos de amostragem probabilísticos, aumentando assim a validade externa dos resultados e sua capacidade de generalização.

Ainda como sugestões para pesquisas futuras, faz-se necessário a aplicação do modelo em uma IES de cunho público, para verificar a adequação dos construtos. Convém destacar que a comparação entre alunos entrantes e alunos formandos deva ser feita como alternativa para verificar a modificação dos construtos ao longo da interação acadêmica. Neste mesmo raciocínio, a pesquisa com ex-alunos mostra-se uma forma importante para mensurar a lealdade e seus antecedentes em indivíduos que, à priori, não encontram-se mais em contato direto com a IES.

Por fim, conclui-se que a lealdade em ambientes de ensino superior deve ser alvo de estudos que envolvam a compreensão dos seus antecedentes e as possíveis implicações destes construtos na manutenção e criação de relacionamentos. 


\section{REFERÊNCIAS}

ANDERSON, E. W.; SULLIVAN M. The Antecedents and Consequences of Customer Satisfaction for Firms. Marketing Science, v. 12, n. 2, p.125-143, 1993.

ANDERSON, J. C.; GERBING, D. W. Structural equation modeling in practice: A review and recommended two-step approach. Psychological Bulletin, v. 103, n. 3, p. 411, 1988.

BAGOZZI, R. P.; YI, Y.; PHILLIPS, L. W. Assessing Construct Validity in Organizational Research. Administrative Science Quarterly, v. 36, n. 3, p. 421-458, 1991.

BEJOU, D.; ENNEW, C. T.; PALMER, A. Trust, Ethics and Relationship Satisfaction. International Journal of Bank Marketing, v. 16, n. 4, p. 170-175, 1998.

BERRY, L. Playing Fair in Retailing. Arthur Anderson Retailing Issues Newsletter, v. 5, n. $2,1993$.

BERRY, L. Relationship Marketing of Services: Growing Interest, Emerging Perspectives. Journal of Academy of Marketing Science, v. 23, n. 4, p. 236-245, 1995.

BERRY, L.; PARASURAMAN, A. Marketing Services. New York: The Free Press, 1991.

BITNER, M. J. Building Service Relationships: It's All About Promisses. Journal of the Academy of Marketing Service, v. 23, n. 4, p. 246-251, 1995.

BOULDING, W.; KALRA, A.; STAELIN, R.; ZEITHAML, V. A. A Dynamic Process Model of Service Quality: From Expectations to Behavioral Intentions. Journal of Marketing Research, v. 30, n.1, p. 7-27, 1993.

BREI, V. A.; ROSSI, C. A. V. Confiança, valor percebido e lealdade em trocas relacionais de serviço: um estudo com usuários de internet banking no Brasil. Revista de Administração Contemporânea, v. 9, n. 2, p. 145-168, 2005.

CHAUDHURI, A.; HOLBROOK, M. B. The Chain of Effects from Brand Trust and Brand Affect to Brand Performance: The Role of Brand Loyalty. Journal of Marketing, v. 65, n. 2, p. 81-94, 2001.

CHO, J. E.; HU, H. The effect of service quality on trust and commitment varying across generations. International Journal of Consumer Studies, v. 33, n. 4, p. 468-476, 2009. 
DE RUYTER, K.; MOORMAN, L.; LEMMINK, J. Antecedents of commitment and trust in customer-supplier relationships in high technology markets. Industrial Marketing Management, v. 30, n. 3, p. 271-286, 2001.

DEAN, A. M. The impact of the customer orientation of call center employees on customers' affective commitment and loyalty. Journal of Service Research, v. 10, n. 2, p. 161-173, 2007.

DICK, A. S.; BASU, K. Customer loyalty: Toward an Integrated Conceptual Framework. Journal of the Academy of Marketing Science, v. 22, n. 2, p. 99-113, 1994.

DWYER, F. R.; SCHURR, P. H.; OH, S. Developing Buyer-Seller Relationships. Journal of Marketing, v. 51, n. 2, p.11-27, 1987.

EISINGERICH, A. B.; BELL, S. J. Perceived service quality and customer trust: does enhancing customers' service knowledge matter? Journal of Service Research, v. 10, n. 3, p. 256-268, 2007.

EVANSCHITZKY, H.; IYER, G. R.; PLASSMANN, H.; NIESSING, J.; MEFFERT, H. The relative strength of affective commitment in securing loyalty in service relationships. Journal of Business Research, v. 59, n. 12, p. 1207-1213, 2006.

FORNELL, C.; LARCKER, D. F. Evaluating Structural Equation Models with Unobservable Variables and Measurement Error: Algebra and Statistics. Journal of Marketing Research, v. 18 , n. 3, p. 382-388, 1981.

FULLERTON, G. The service quality-loyalty relationship in retail services: does commitment matter? Journal of Retailing and Consumer Services, v. 12, n. 2, p. 99-111, 2005 .

GARBARINO, E.; JOHNSON, M. S. The Different Roles of Satisfaction, Trust, and Commitment in Customer Relationships. Journal of Marketing, v. 63, n. 2, p. 70-87, 1999.

GOUNARIS, S.; STATHAKOPOULOS, V. Antecedents and Consequences of Brand Loyalty: An Empirical Study. Journal of Brand Management, v. 11, n. 4, p. 283-306, 2004.

GRÖNROOS, C. From Marketing Mix to Relationship Marketing: Towards a Paradigm Shift in Marketing. Periodical Management Decision, v. 32, n. 2, p. 4-18, 1994.

HAIR, J. F.; ANDERSON, R. E.; TATHAM, R. L.; BLACK, W. C. Multivariate Data Analysis. Upper Saddle River: Prentice-Hall, 1998. 
HENNIG-THURAU, T.; KLEE, A. The Impact of Customer Satisfaction and Relationship Quality on Customer Retention - A Critical Reassessment and Model Development. Psychology \& Marketing, v. 14, n. 8, p. 737-764, 1997.

HENNIG-THURAU, T.; LANGER, M. F.; HANSEN, U. Modeling and Managing Student Loyalty: An Approach Based on the Concept of Relationship Quality. Journal of Service Research, v. 3, n. 4, p. 331-344, 2001.

INEP - INSTITUTO NACIONAL DE ESTUDOS E PESQUISAS EDUCACIONAIS. Censo da Educação Superior - Relatório Técnico 2010. Disponível em: <http://www.inep.gov.br>. Acesso em: Jul. 2012.

KRAMER, R. Trust and Distrust in Organizations: Emerging Perspectives, Enduring Questions. Annual Review of Psychology, v. 50, p. 569-598, 2000.

LARAN, J. A.; ESPINOZA, F. S. Consumidores Satisfeitos, e Então? Analisando a Satisfação como Antecedente da Lealdade. Revista de Administração Contemporânea, v. 8, n. 2, p. 51-70, 2004.

MACKINTOSH, G.; LOCKSHIN, L. S. Retail Relationships and Store Loyalty: A Multilevel Perspective. International Journal of Research in Marketing, v. 14, n. 5, p. 487-497, 1997.

MALHOTRA, N. Pesquisa de Marketing: Uma Orientação Aplicada. 4. ed. Porto Alegre: Bookman, 2006.

MASTERSON, S. S.; LEWIS, K.; GOLDMAN, B. M.; TAYLOR, M. S. Integrating Justice and Social Exchange: The Differing Effects of Fair Procedures and Treatment on Work Relationships. Journal of the Academy of Management, v. 43, n. 4, p. 738-748, 2000.

MOORMAN, C.; DESHPANDÉ, R.; ZALTMAN, G. Factors Affecting Trust in Marketing Research Relationships. Journal of Marketing, v. 57, n. 4, p. 81-101, 1993.

MOORMAN, C.; ZALTMAN, G.; DESHPANDÉ, R. Relationships Between Providers and Users of Market Research: The Dynamics of Trust Within and Between Organizations. Journal of Marketing Research, v. 29, n. 3, p. 314-328, 1992.

MORGAN, R.; HUNT, S. The commitment-Trust Theory of Relationship Marketing. Journal of Marketing, v. 58, n. 3, p. 20-38, 1994. 
NETO, M. R. A.; MOURA, A. I. Construção e Teste de um Modelo Teórico de Marketing de Relacionamento para o Setor de Educação. In: Anais... ENANPAD, 28, 2004, Curitiba (PR).

NEWMAN, J. W.; WERBEL, R. A. Multivariate Analysis of Brand Loyalty for Major Household Appliances. Journal of Marketing Research v. 10, n. 4; p. 404-410, 1973.

OLIVER, R. L. Whence Consumer Loyalty? Journal of Marketing, v. 63, p. 33-44, 1999.

PARASURAMAN, A.; BERRY, L.L.; ZEITHAML, V. A. Refinement and Reassessment of the SERVQUAL Scale. Journal of Retailing, v. 67, n. 4, p. 420-450, 1991.

PARASURAMAN, A.; GREWAL, D. The Impact of Technology on the Quality- ValueLoyalty Chain: A Research Agenda. Journal of the Academy of Marketing Science, v. 28, n. 1, p. 9-16, 2000.

PERIN, M. G.; SAMPAIO, C. H.; BREI, V. A.; PORTO, C. A. As Relações entre Confiança, Valor e Lealdade: um Estudo Intersetorial. In: Anais... ENANPAD, 28, 2004, Curitiba (PR).

PRADO, P. H. M.; SANTOS, R. C. Comprometimento e Lealdade: Dois Conceitos ou Duas Dimensões de um Único Conceito? In: Anais... ENANPAD, 27, 2003, São Paulo (SP).

PRITCHARD, M. P.; HAVITZ, M. E.; HOWARD, D. R. Analyzing the CommitmentLoyalty Link on Service Contexts. Journal of the Academy of Marketing Science, v. 27, n. 3, p. 333-348, 1999.

REICHHELD, F. F.; SASSER, W. E. Zero Defections: Quality Comes to Services. Harvard Business Review, Sep/Oct, 1990.

RUST, R. T.; ZEITHAML, V.; LEMON, K. N. O valor do cliente. Porto Alegre: Bookman, 2001.

SINGH, J.; SIRDESHMUKH, D. Agency and Trust Mechanisms in Consumer Satisfaction and Loyalty Judgments. Journal of the Academy Marketing Science, v. 28, n. 1, p. 150$167,2000$.

SIRDESHMUKH, D.; SINGH, J.; SABOL, B. Consumer Trust, Value, and Loyalty in Relational Exchanges. Journal of Marketing, v. 66, n. 1, p. 15-37, 2002. 
SLONGO, L. A.; MÜSSNICH, R. Serviços ao Cliente e Marketing de Relacionamento no Setor Hoteleiro de Porto Alegre. Revista de Administração Contemporânea, v. 9, n. 1, p. 149-170, 2005.

SUI, J. J.; BALOGLU, S. The role of emotional commitment in relationship marketing: An empirical investigation of a loyalty model for casinos. Journal of Hospitality \& Tourism Research, v. 27, n. 4, p. 470-489, 2003.

SWAN, J. E.; NOLAN, J. K. Gaining Customer Trust: A Conceptual Guide for the Salesperson. Journal of Selling and Sales Management, v. 5, n. 2, p. 39-48, 1985.

VENKATESH, U. The Importance Of Managing Points-Of-Marketing In Marketing Higher Education Programmes - Some Conclusions. Journal of Services Research, v. 1, n. 1, p. 125-141, 2001.

VIEIRA, V. A.; DAMACENA, C. Loyalty in the Supermarket. Brazilian Administration Review, v. 4, n. 3, p. 47-62, 2007.

WOODRUFF, R. B. Customer Value: The Next Source for Competitive Advantage. Journal of the Academy of Marketing Science, v. 25, n. 2, p. 139-153, 1997.

ZEITHAML, V. A.; BERRY, L. L.; PARASURAMAN, A. The Behavioral Consequences of Service Quality. Journal of Marketing, v. 60, n. 2, p. 31-46, 1996. 